JGG 2021;69:120-129

doi: $10.36150 / 2499-6564-N 320$

\title{
Trazodone: a multifunctional antidepressant. Evaluation of its properties and real-world use
}

\author{
Alessandro Cuomo ${ }^{1}$, Angelo Bianchetti², Annachiara Cagnin ${ }^{3}$, \\ Domenico De Berardis ${ }^{4}$, Ignazio Di Fazio ${ }^{5}$, Raffaele Antonelli Incalzi ${ }^{6}$, \\ Camillo Marra ${ }^{7}$, Francesca Neviani ${ }^{8}$, Pier Francesco Laurenzi ${ }^{1}$, \\ Ferdinando Nicoletti9 \\ ${ }^{1}$ University of Siena School of Medicine, Siena, Tuscany, Italy; ${ }^{2}$ Medicine and Rehabilitation \\ Department, Istituto Clinico 'S. Anna' Hospital, Brescia, Italy; Associazione Italiana di Psicogeriatria \\ (AIP), Brescia, Italy; Società Italiana di Geriatria e Gerontologia (SIGG), Firenze, Italy; ${ }^{3}$ Department \\ of Neurosciences, Sciences NPSRR, University of Padua Medical School, Padua, Italy; ${ }^{4}$ National \\ Health Service, Department of Mental Health, Psychiatric Service of Diagnosis and Treatment, \\ 'G. Mazzini' Hospital, Teramo, Italy; ${ }^{5}$ Ospedale Richiedei, Palazzolo (BR), Italy; ${ }^{6}$ Gerontology Unit, \\ Campus Bio Medico University and Teaching Hospital, Rome, Italy; ${ }^{7}$ Memory Clinic, Neurology \\ Department, Catholic University of Rome, Italy; ${ }^{8}$ Department of Geriatrics, Nuovo Ospedale Civile \\ 'S. Agostino Estense', Modena and Reggio Emilia University, Modena, Italy; ${ }^{9}$ Department of \\ Physiology and Pharmacology University Sapienza of Rome, and IRCCS Neuomed, Pozzilli, Italy
}

Trazodone is indicated for the treatment of Major Depressive Disorder (MDD), often associated with anxiety, insomnia, agitation, nervousness, or irritability.

The aim of this review was to summarise the pharmacological properties of trazodone in improving depressive symptoms in elderly patients and in patients with neurological comorbidities, for whom secondary depression is often present.

Five different pharmaceutical formulations of trazodone are available: intravenous or intramuscular liquid solution, immediate-release tablets (I.R.), oral drops, prolonged-release tablets (P.R.), and extended-release Contramid $^{\circledR}$ tablets (COAD). The initial dose of trazodone should range from 75 to $100 \mathrm{mg} /$ day. For COAD formulation, the starting recommended dose is $150 \mathrm{mg}$ once daily. In elderly patients, trazodone may be administered at very low dosages (25-50 mg/day for I.R. formulation, and 50-100 mg for the P.R. or E.R. formulations). The maximum daily dose should not exceed $300 \mathrm{mg} /$ day, split over two administrations across the day.

In elderly patients, trazodone has reported excellent results, keeping high-quality standards for safety and tolerability. It can help to improve insomnia and anxiety without resorting to benzodiazepines. In patients with neurological conditions, trazodone helps to treat anxiety-depressive symptoms. In patients with Alzheimer's disease or frontotemporal dementia, trazodone can help to handle behavioural symptoms, also acting as a putative neuroprotective agent.

Trazodone is well tolerated. Somnolence/sedation, dizziness, constipation, and blurred vision are common side effects with an incidence slightly greater than $5 \%$. Orthostatic hypotension and headache are relatively common side effects.

The great availability of formulations allows to personalise trazodone administration according to patient profile characteristics.

Key words: trazodone, major depressive disorder, neurological disorder, geriatric population, insomnia 


\section{INTRODUCTION}

Trazodone is indicated for the treatment of depression and has been shown efficacious in reducing most symptoms associated with depression ${ }^{1-3}$.

The peculiar multifunctional pharmacological profile of trazodone explains its efficacy to improve Major Depressive Disease (MDD), a very heterogeneous condition often associated with anxiety, insomnia, agitation, nervousness, or irritability ${ }^{2,4-6}$. To diagnose MDD, an individual must be experiencing five or more symptoms (Tab. I) during the same 2-week period. At least one of the symptoms should be either depressed mood or anhedonia ?

All DSM criterion symptoms, except depressed mood, comprise at least two sub-symptoms, and three of the criterion symptoms (sleep, weight/appetite, psychomotor) can be met by either increases or decreases. Therefore, up to 16,400 possible symptom profiles can generate a diagnosis of MDD ${ }^{8}$. Furthermore, the transdiagnostic determinants and the DSM- 5 specifiers (e.g., with anxious distress or with psychotic features) generate a much higher number of clinically relevant profiles $^{9,10}$.

Recent studies investigated the efficacy of particular antidepressants in improving symptoms for specific phenotypical profiles, thus showing how the selection of the best drug for a given cluster could be the new personalised approach for depression ${ }^{11}$.

In such context, trazodone can represent an efficacious treatment for the geriatric population.

In the elderly population, the risk of depression is high ${ }^{12}$. In patients with one or more chronic illnesses or disabling conditions, secondary depression can be induced by pharmacological treatments ${ }^{13}$. Furthermore, depression can aggravate the chronic disease and vice versa could be exacerbated by the chronic disease itself. For

Table I. MDD Symptoms.

\begin{tabular}{|l|}
\hline Depressed mood most of the day \\
\hline $\begin{array}{l}\text { Diminished interest or loss of pleasure in almost all activities most of } \\
\text { the day (anhedonia) }\end{array}$ \\
\hline $\begin{array}{l}\text { Significant weight change or appetite decrease or increase nearly } \\
\text { every day }\end{array}$ \\
\hline Sleep disturbance (insomnia or hypersomnia) \\
\hline Psychomotor agitation or retardation nearly every day \\
\hline Fatigue or loss of energy nearly every day \\
\hline Feelings of worthlessness nearly every day \\
\hline $\begin{array}{l}\text { Diminished ability to think or concentrate; indecisiveness nearly every } \\
\text { day }\end{array}$ \\
\hline $\begin{array}{l}\text { Recurrent thoughts of death, recurrent suicidal ideation without a } \\
\text { specific plan, or a suicide attempt or specific plan for committing } \\
\text { suicide }\end{array}$ \\
\hline
\end{tabular}

example, heart disease and depression can be reciprocally worsened.

Symptoms of depression in the elderly differ from those in the young. Sleep disturbance and agitation may prevail in elderly patients. Other symptoms, as confusion or impaired attention, may be misinterpreted as a neurological disorder (i.e., Alzheimer's disease).

In patients with neurological conditions, secondary depression is common. Epilepsy, stroke, Parkinson's disease, and other neurological illnesses reported a high prevalence of secondary depression. Sleep disorder, fatigue, poor concentration, or disturbed appetite are also present. Antidepressants may improve symptoms, quality of life, and overall survival in patients with neurological disorders ${ }^{14}$. The aim of this narrative review was to summarise the pharmacological properties of trazodone in elderly patients and patients with neurological comorbidities. Moreover, this work also investigated trazodone efficacy on some specific symptoms as sleep disturbance, anxiety, agitation, and substance abuse. Two case reports were reported.

\section{PHARMACOLOGICAL PROPERTIES}

\section{Pharmacodynamics}

Trazodone is a Serotonin Receptor Antagonist and Reuptake Inhibitor (SARI) ${ }^{2}$ due to its affinity profile for the serotonin reuptake transporter (SERT) and serotonin receptors ${ }^{15}$. Trazodone behaves as a potent antagonist of $5-\mathrm{HT}_{2 \mathrm{~A}}$ and $5-\mathrm{HT}_{2 \mathrm{~B}}$ receptors, an antagonist of $5-\mathrm{HT} \mathrm{T}_{1 \mathrm{D}}$, $5-\mathrm{HT}_{2 \mathrm{C}}, \mathrm{a}_{1 \mathrm{~A}}, \mathrm{a}_{2 \mathrm{C}} \mathrm{H}_{1}$ receptors with moderate affinity, a partial agonist of $5-\mathrm{HT}_{1 \mathrm{~A}}$ receptors, and an inhibitor of SERT (Tab. II). At therapeutic dose, trazodone has no activity at muscarinic cholinergic receptors, dopamine receptors, and dopamine or noradrenaline transporters. Similar to other antidepressants, it inhibits serotonin reuptake ${ }^{16}$. The multi-target profile of trazodone provides the following clinical advantages:

1 The partial agonist activity at 5- $\mathrm{HT}_{1 \mathrm{~A}}$ receptor may facilitate desensitisation of $5-\mathrm{HT}_{1 \mathrm{~A}}$ receptors in serotonergic projecting neurons of the dorsal raphe nucleus, thereby allowing a rapid antidepressant action $^{17}$ and may contribute to the anxiolytic activity of trazodone, as suggested by preclinical studies ${ }^{18}$;

$25-\mathrm{HT}_{2 \mathrm{~A}}$ and $5-\mathrm{HT}_{2 \mathrm{C}}$ receptor blockade may limit the incidence of sexual dysfunction, usually associated with serotonergic drugs ${ }^{19}$;

3 Antagonism at 5- $\mathrm{HT}_{2 \mathrm{~A}}, \alpha_{1 \mathrm{~A}}$, and $\mathrm{H}_{1}$ receptors confer sedative and hypnotic properties ${ }^{20,21}$. Trazodone may treat the symptoms of hypoactive sexual desire disorder and antidepressant-associated sexual dysfunction because of its 5-HT2 antagonism 22-24; 
Table II. Pharmacodynamic profile of trazodone.

\begin{tabular}{|l|c|c|}
\hline Receptor & Ki (nM) & Effects \\
\hline SERT & 367.3 & Antagonist \\
\hline $5-H T_{1 A}$ & 118 & Partial agonist \\
\hline $5-\mathrm{HT}_{1 \mathrm{D}}$ & 106 & Antagonist \\
\hline $5-\mathrm{HT}_{2 \mathrm{~A}}$ & 35.8 & Antagonist \\
\hline $5-\mathrm{HT}_{2 \mathrm{~B}}$ & 78.4 & Antagonist \\
\hline $5-\mathrm{HT}_{2 \mathrm{C}}$ & 223.9 & Antagonist \\
\hline$\alpha_{1 \mathrm{~A}}$ & 153 & Antagonist \\
\hline$\alpha_{2 \mathrm{C}}$ & 155 & Antagonist \\
\hline $\mathrm{H}_{1}$ & 220 & Antagonist \\
\hline
\end{tabular}

Source data: Psychoactive Drug Screening Program (PDSP) database. $\mathrm{K}_{\mathrm{i}}$ values are inversely proportional to the binding affinity of the drug for the target

4 The moderate affinity for $5-\mathrm{HT}_{2 \mathrm{C}}$ and $\mathrm{H}_{1}$ receptors may limit the risk of weight gain.

\section{Pharmacokinetics}

To date, at least five different pharmaceutical preparations of trazodone are available in the European Union (E.U.) or USA markets: 1) intravenous or intramuscular liquid solution, 2) immediate-release tablets (I.R.), 3) oral drops, 4) prolonged-release tablets (P.R.), and 5) extended-release Contramid ${ }^{\circledR}$ tablets (COAD).

Some pharmacokinetic parameters $\left(\mathrm{C}_{\max }, \mathrm{T}_{\max }\right.$, and elimination half-life $t_{1 / 2}$ ) could differ according to the drug formulation (Table III). Trazodone is extensively metabolised by CYP-450 3A4. More than 99\% of bioavailable trazodone is converted via oxidative cleavage to metachlorophenylpiperazine (mCPP), an active metabolite further metabolised by CYP2D6 ${ }^{25}$. Meta-chlorophenylpiperazine concentrations in vivo range from 1 to $20 \%$ of those of the parent drug ${ }^{26}$. Thus, the contribution of $\mathrm{mCPP}$ to the overall clinical activity is unclear. Trazodone has shown a serum protein binding of $90-95 \%$, resulting in a bloodstream free fraction of 5-10\%. Elimination predominantly follows the renal route. Trazodone pharmacokinetics approximates a two-compartment distribution model 20 . Because of its hydrophobic features, this compound easily binds to fat tissues and crosses cell membranes ${ }^{27}$. The oral bioavailability of trazodone is mostly affected by food. $C_{\max }$ value increases by $86 \%$ when the drug is administered with food ${ }^{28}$.

\section{DOSAGES}

\section{General ReCommendations}

According to EMA guidelines, the initial dose of trazodone should range from 75 to $100 \mathrm{mg} /$ day, administered in a single dose before bedtime. Dosage should be adjusted accordingly to clinical responses, up to $300 \mathrm{mg} /$ day, split over two administrations across the day. Trazodone reaches the steady-state levels in about two days. The recommended starting dose of COAD is $150 \mathrm{mg}$ once daily in adults. The dose may be increased by $75 \mathrm{mg} /$ day every three days (i.e., start $225 \mathrm{mg}$ on Day 4 of therapy). The maximum daily dose should not exceed $300 \mathrm{mg}^{29}$.

\section{FORMULATIONS}

The availability of different formulations (Table III) ensures the efficacy of trazodone in a wide range of

Table III. Pharmacokinetics.

\begin{tabular}{|c|c|c|c|c|c|}
\hline Trazodone & Formulations & Cmax & Tmax & $t 1 / 2$ & Food interaction \\
\hline $\mathrm{TZ}_{\mathrm{IR}}$ & $\begin{array}{c}50 \mathrm{mg} \text { tablets } \\
100 \mathrm{mg} \text { tablets } \\
25 \mathrm{mg} / \mathrm{ml} \text { drops } \\
60 \mathrm{mg} / \mathrm{ml} \text { drops }\end{array}$ & $1.2-1.6 \mu \mathrm{g} / \mathrm{ml}$ & $1 \mathrm{~h}$ (1.5 h elderly) & $\begin{array}{c}6.6 \mathrm{~h} \\
(9-11 \mathrm{~h} \text { at } \\
\text { steady state })\end{array}$ & Slow absorption \\
\hline $\mathrm{TZ}_{\mathrm{IV/M}}$ & $\begin{array}{c}50 \mathrm{mg} / 5 \mathrm{ml} \\
\text { solution for injection }\end{array}$ & NA & Immediate & $6-8-h$ & No effect \\
\hline$T Z_{P R \text { film-coated }}$ & $\begin{array}{c}75 \mathrm{mg} \text { tablets } \\
150 \mathrm{mg} \text { tablets }\end{array}$ & $0.7-1.2 \mu \mathrm{g} / \mathrm{mL}$ & $4 \mathrm{~h}$ & $12 \mathrm{~h}$ & No effect \\
\hline $\mathrm{TZ}_{\mathrm{COAD}}$ & $\begin{array}{l}150 \mathrm{mg} \text { tablets } \\
300 \mathrm{mg} \text { tablets }\end{array}$ & $\begin{array}{c}\sim 1.5 \mathrm{mg} / \mathrm{L} \text { (steady } \\
\text { state) } \\
2 \pm 0.635 \mu \mathrm{g} / \mathrm{mL}\end{array}$ & $7.57 \pm 2.3 \mathrm{~h}$ & $10 \mathrm{~h}$ & $\begin{array}{c}\text { Increased absorption } \\
\text { Administration of } \mathrm{TZ}_{\mathrm{COAD}} 300 \mathrm{mg} \\
\text { once daily provides equivalent } \\
\text { steady-state exposure to, with a } \\
\text { lower } \mathrm{C}_{\max } \text { than, } \mathrm{TZ}_{\mathbb{R}} 100 \mathrm{mg} \text { given } \\
3 \text { times a day. } \mathrm{A} \text { high-fat meal } \\
\text { increases } \mathrm{C}_{\max } \text {, but there is no } \\
\text { substantial effect on AUC. }\end{array}$ \\
\hline
\end{tabular}


clinical scenarios. For example, the immediate-release (I.R.) formulation (available as tablets or liquid drops) reaches maximum blood levels in about an hour, ensuring rapid effects for symptoms like insomnia ${ }^{22}$. The relatively short elimination half-life (6h) reduces the risk of morning drowsiness ${ }^{30}$. The prolonged-release (P.R.) formulation is characterised by a film coating, which ensures slow release into the bloodstream. The extended-release (COAD) formulation provides an even more gradual and continuous absorption of the drug into the bloodstream. It allows a simplified once-a-day prescription schedule, thus enhancing adherence, improving tolerability, and avoiding see-sawing blood concentration patterns ${ }^{30}$.

\section{REAL WORD ISSUES \& EXPERT OPINION: IDEAL TARGETED DISORDERS FOR TRAZODONE}

\section{DEPRESSION IN ELDERLY PATIENTS}

Trazodone is clinically useful in elderly patients, including people with agitated behaviour, because of its specific anxiolytic and sleep normalising effect and excellent safety and tolerability ${ }^{31}$. In elderly patients, a very low starting dose is recommended, usually no more than 25-50 mg/day for the I.R. formulation or 50-100 mg for the P.R. or E.R. formulations. However, ageing does not significantly impair liver metabolism by CYP3A4, while the reduced renal clearance may increase trazodone blood concentrations ${ }^{32}$.

When treating elderly patients, the once-a-day COAD formulation may be the best choice to rapidly reach therapeutic doses while minimising side effects (i.e., orthostatic hypotension). The liquid formulation may be preferred if dysphagia or other difficulties in administration are present. Drops may represent an advantage when small dosage changes are necessary. The rapid peak effect of the I.R. formulations (drops or tablets) also enables appropriate insomnia management. In our experience, most elderly depressed patients improve with doses as low as 100 mg/day. Finally, the dual action of trazodone on anxiety and depression is particularly useful to reduce benzodiazepines, which are burdened by several risks in elderly patients.

\section{DEPRESSION WITH NEUROLOGICAL COMORBIDITIES}

Special populations such as depressed elderly patients may also be at high risk of dementia and cognitive impairment, for which depression has been reported as a risk factor or an early harbinger ${ }^{33}$. Trazodone helps to treat anxiety-depressive symptoms associated with subcortical dementias, Parkinsonism, and movement or behavioural disorders. It may be efficacious in treating behavioural symptoms of Alzheimer's disease ${ }^{34}$ and frontotemporal dementia ${ }^{35}$. Interestingly, trazodone might cause neuroprotection by inhibiting the pancreatic endoplasmic reticulum kinase and eukaryotic initiation factor-2a (PERK/EIF-2a) unfolded protein response pathway ${ }^{36}$. Sustained activation of this pathway, which is associated with Alzheimer's disease, frontotemporal dementia, and other neurodegenerative disorders characterised by protein misfolding ${ }^{37-39}$, causes translation repression, with ensuing neurodegeneration ${ }^{36}$. This unique property of trazodone suggests that this drug might be particularly valuable for treating depression associated with insomnia in patients with chronic neurodegenerative disorders, particularly in the early phases of neurodegeneration. In neurodegenerative disorders, trazodone behaves as a putative neuroprotective agent because it may promote the secretion of neurotrophic factors from cultured human astrocytes ${ }^{40}$.

Furthermore, the absence of anticholinergic effects of trazodone is a further advantage in treating depression associated with Alzheimer's disease. The use of tricyclic antidepressant drugs and several antipsychotic agents in Alzheimer's disease is seriously limited by the anticholinergic activity of these drugs, which may further impair cognition ${ }^{41,42}$. On the contrary, recent retrospective analysis has reported an association between trazodone treatment and delayed cognitive decline in a sample of patients affected by Alzheimer's disease ${ }^{43}$.

\section{Depression With SLEeP DISTURBances}

Insomnia is a condition that could significantly impact daytime activities because of a change of the sleeping pattern (difficulties with falling and staying asleep or waking too early). While primary insomnia has an unknown aetiology, secondary insomnia is usually induced by psychiatric or physical conditions or some external factors. There is strong evidence about the effectiveness of trazodone in the treatment of both primary and secondary insomnia ${ }^{44}$. Trazodone improves sleep mainly by increasing total sleep time, enhancing delta sleep entry, and decreasing the number of night-time awakenings ${ }^{45}$. It maintains these qualities in healthy and depressed-insomniac patients ${ }^{46,47}$. However, the antidepressant efficacy of trazodone seems unrelated to the severity of insomnia at baseline ${ }^{2}$. Roth et al. (2011) observed that a $50 \mathrm{mg}$ dose of trazodone required one week to ameliorate the delta sleep phase, while $100 \mathrm{mg}$ showed a positive effect after 1-2 days ${ }^{48}$.

\section{DEPRESSION IN COMORBIDITY WITH OTHER CONDITIONS}

\section{Agitation and behavioural disturbances}

Depressed patients can manifest verbal or physical aggressiveness, especially if anxiety symptoms, 
depressive episodes with mixed features, or comorbid dementia are present ${ }^{49,50}$. Conversely, elderly patients with dementia who manifest physical or verbal aggression showed a higher prevalence of depression ${ }^{51}$. Trazodone inhibits aggressiveness ${ }^{52}$, probably due to its association of a combined serotoninergic antidepressant activity and $\mathrm{H} 1$ histamine receptor blockade at low doses (i.e., 50-75 mg/day). Other drugs used to treat aggressive behaviour associated with depression (e.g., benzodiazepines) may cause falls, tolerance, physical dependence, and cognition impairment. Moreover, post-stroke patients often display depressive symptoms with emotional and behavioural changes such as anger, hostility, and impulsivity ${ }^{53}$. Of note, trazodone showed beneficial effects at $300 \mathrm{mg} / \mathrm{die}$ in post-stroke depression ${ }^{54}$

Preclinical findings have hypothesised that trazodone may restrain L-DOPA-induced dyskinesia and psychosis-like behaviours in Parkinson's disease ${ }^{55}$. Trazodone administration was also beneficial in a sample of bipolar inpatients affected by psychomotor agitation ${ }^{56}$. Other studies showed a good efficacy of trazodone in patients with agitation ${ }^{57}$ and antipsychotic-induced akathisia ${ }^{58}$.

\section{Depression and anxiety}

A large body of evidence supports the value of trazodone for treating generalised anxiety disorder ${ }^{59}$ or posttraumatic stress disorder (PTSD) ${ }^{60}$. In both conditions, trazodone improved sleep disturbances ${ }^{5}$. It may be of particular help in patients with anxiety disorders who are at risk for benzodiazepine abuse ${ }^{5}$.

\section{Depression and substance abuse induced sleep disturbance}

The reward deficiency syndrome that includes both dysphoric and depressive symptoms may appear after cocaine detoxification. A 9-patient study about X.R. trazodone formulation for the treatment of cocaine withdrawal symptoms has hypothesised that trazodone may improve the reduction of craving and reduce psychological symptoms, although its efficacy to avoid early relapse should be further confirmed ${ }^{61}$.

Depression is commonly represented in substance abuse and usually unrecognised. Proper diagnosis of mood disturbance could prevent episodes of relapse and reduce suicide rates in this patient population. It would be necessary for routine clinical practice to recognise if a patient has primary or substance-induced depression to avoid treatment delay ${ }^{62}$.

Sleep disturbance is frequent during alcohol withdrawal. A randomised, double-blind placebo-controlled trial showed that low doses of trazodone could improve sleep quality during alcohol withdrawal. However, the effect was lost once trazodone was discontinued ${ }^{63}$.

\section{SAFETY AND TOLERABILITY}

Trazodone is well tolerated in MDD patients ${ }^{2,22}$. The most common side effects are somnolence/sedation, dizziness, constipation, blurred vision. The incidence of these side effects is greater than $5 \%$ and is double that of placebo ${ }^{64}$. Other bothersome or relatively common side effects include orthostatic hypotension and headache ${ }^{2,22,65}$. Orthostatic hypotension may be more severe if an antihypertensive agent is associated. In the geriatric population, falls may occur more frequently 66,67 .

Priapism is a rare adverse effect, likely due to $\alpha$-adrenergic receptor blockade 66,68,69. Trazodone should be used with caution to reduce the risk of priapism in patients affected by multiple myeloma, sickle cell anaemia, hypercoagulable states, leukaemia, autonomic nervous system dysfunctions, and anatomical deformation of the penis (e.g., Peyronie's disease, angulation, or cavernosal fibrosis), or in combination with SSRIs, cocaine, or atypical antipsychotics ${ }^{2,70}$.

\section{HOW tO MANAGE THE ADVERSE EFFECTS OF TRAZODONE}

\section{Orthostatic hypotension and dizziness}

Trazodone has an excellent cardiovascular safety profile ${ }^{71}$, although mild orthostatic hypotension can occur. Therefore, it is recommended to measure blood pressure before administration and advise the patient to remain seated or in bed for at least 30 minutes after administration and not to change position too quickly. A recent investigation on a small sample of real-world elderly depressed patients reported no significant associations between QTC variations and trazodone administration ${ }^{72}$. Trazodone may also cause dizziness, which is a consequence of $\alpha$-adrenergic receptor blockage, and usually occurs when large doses of the drug are taken on an empty stomach ${ }^{65}$. Due to the inhibition of small muscle contraction, patients may have a subjective feeling of losing balance and dizziness in more severe cases. In such cases, patients should lay down, rest, and avoid rapid movements. Proper hydration is recommendable, avoiding caffeine, nicotine, or alcohol ${ }^{73}$.

\section{Headache}

Trazodone may induce headache. This effect is mediated by the active metabolite, mCPP, which, as opposed to trazodone, acts as an agonist at various serotonin receptors and may also enhance serotonin release ${ }^{74}$. Trazodone-induced headaches may not respond to conventional analgesics, and, therefore, can only be managed by suspending the treatment ${ }^{75}$.

\section{Sedation}

Sedation during daytime sleepiness is a common adverse effect of trazodone ${ }^{76}$. Daytime sleepiness 
might contribute to fatigue, decreased quality of life, and increased risk of occupational or car accidents ${ }^{77}$. Dosage adjustments, change in trazodone formulation (e.g., switching to the I.R. formulation, administered in the evening), and behavioural interventions, such as going to bed early ${ }^{78}$, can improve symptomatology.

\section{Gastrointestinal symptoms}

Nausea and other gastrointestinal symptoms may occur if the agent is taken at high doses on empty stomach. Thus, taking trazodone with food is recommended ${ }^{65}$. For dry mouth, the use of oral lubricating gels, artificial saliva, or chewing gum might help to enhance salivation ${ }^{79}$.

\section{Overdose}

Trazodone is a safe drug. Doses of $500 \mathrm{mg}$ per $\mathrm{kg}$ are lethal for experimental animals. In contrast, doses as high as $10 \mathrm{~g}$ may not cause death in humans ${ }^{65}$. High doses of trazodone may seldom cause serotonin syndrome, a life-threatening condition due to serotonin accumulation ${ }^{80}$. The most common systems involved in trazodone overdose are respiratory, cardiovascular, nervous, and gastrointestinal systems ${ }^{81}$.

At toxic blood concentrations, trazodone may cause prolongation of Q.T. interval and torsade de pointes. Cases of life-threatening cardiac arrhythmias have been reported even at regular doses. Concomitant use of trazodone with drugs known to prolong the Q.T. interval or causing cardiac toxicity should be avoided ${ }^{2}$.

\section{Contraindications - warnings}

Trazodone should not be used in combination with monoamine oxidase inhibitors (MAOls). Caution is needed when trazodone is co-administrated with drugs that increase serotonin levels for the potential risk of serotonin syndrome ${ }^{82}$.

In patients with liver failure, trazodone should be avoided ${ }^{83}$. It should not be used during intoxication with alcohol or hypnotic agents or in patients with myocardial infarction ${ }^{84}$.

\section{CASE SCENARIOS}

\section{CASE 1: DePRESSION IN PATIENTS WITH NeUROLOGICAL DISORDERS}

A 51-year-old woman, divorced, without sons, was diagnosed with multiple sclerosis. Since she lost had her job, she experienced a depressed mood, sleeping problems, apathy, difficulty performing daily activities, and increased appetite. She also complained of anxiety, aggravation, restlessness, muscle tension, poor concentration, and fatigue. Her primary care physician prescribed her clonazepam, which she gradually increased up to $8 \mathrm{mg} /$ day without consulting her doctor. After two years, since she reported depressed mood, severe anxiety, poor concentration, poor memory, increased appetite, and suicidal thoughts, she was hospitalised. X.R. trazodone $150 \mathrm{mg}$, to be taken before bedtime, was prescribed. Clonazepam was gradually decreased to $6 \mathrm{mg}$ on day $1,4 \mathrm{mg}$ on day 2, $3 \mathrm{mg}$ on days 3 and $4,2 \mathrm{mg}$ on days 6 and 7 , and $1 \mathrm{mg}$ on days 8 and 9 , followed by discontinuation. During hospitalisation, the patient also received intensive psychotherapy. After three days, trazodone was increased to $225 \mathrm{mg}$, and after another three days, the dose was further increased to $300 \mathrm{mg}$. She showed a gradual improvement in mood, anxiety, and cognitive functions. Trazodone was also combined with prolonged-release quetiapine to improve mood and anxiety. Quetiapine was started at $50 \mathrm{mg}$, to be taken in the morning, and gradually increased up to $200 \mathrm{mg}$, always to be taken in the morning. Two weeks after discharge from the hospital, the patient complained about moderate daytime sleepiness, which improved after discontinuing quetiapine. COAD trazodone was continued at $300 \mathrm{mg}$ in the evening. Excellent results were reported.

\section{CASE 2: DEPRESSION IN A GeRIATRIC PATIENT WITH COGNITIVE IMPAIRMENT}

A 75-year-old widow with three sons showed mild attention deficit and difficulty planning actions, abstracting thoughts, and finding words and names for commonly used objects. In the following two years, her condition deteriorated significantly: memory loss, difficulty recognising familiar people and places, disorientation, inability to acquire new information, and a gradual tendency to neglect her hygiene and nutrition were registered. Therefore, she was admitted to an assisted health residence. Later, she experienced apathy, loss of interest, refusal to get out of her bed, reluctance to eat, insomnia, anxiety, depressed mood, crying spells, and pessimistic thoughts. After a thorough assessment, she was diagnosed with depression, comorbid to cognitive impairment. So far, memantine at the dose of $10 \mathrm{mg} /$ day was administered. Later, COAD trazodone $150 \mathrm{mg}$, half tablet to be taken in the evening, was prescribed. After three days, her insomnia and anxiety improved, and no side-effects were reported. She started to eat again. COAD trazodone was increased to 1 tablet in the evening with a progressive and clear-cut improvement of sleep, anxiety, mood, appetite, and interests. After about five weeks of trazodone treatment, the patient was completely free of depressive symptoms. 


\section{CONCLUSIONS}

Major depressive disorder is a great public health challenge, the leading worldwide cause of disability. The complexity and heterogeneity of this condition have always been the object of clinicians. Many efforts have been made to identify antidepressants and personalised formulations in improving symptoms according to the different patient profiles. There is evidence that a range of depressive patient profiles, including elderly patients and those with underlying neurological conditions, sleep disturbance, agitation, or substance abuse, may benefit from trazodone.

The efficacy, safety, and tolerability of trazodone are widely proven. Different formulations allow personalised treatments, thus improving specific symptoms associated with depression MDD, like insomnia, anxiety, agitation, or nervousness. The COAD formulation offers the advantage of once-a-day administration and the possibility to start with a dose $(150 \mathrm{mg})$ that is already potentially effective for depression, along with a steady, gradual release of the medication in the bloodstream throughout 24 hours. The PR formulation offers the advantage of an evening administration (up to $150 \mathrm{mg}$ ) for patients (e.g., those with middle and late awakenings) who need drug exposure during the night and a maximum blood concentration at approximately 4 hours from drug intake. The I.R. formulation offers the advantage of reaching the maximum blood concentration after 1-2 hours, and this is particularly valuable for depressive patients with initial-early insomnia. Intravenous and intramuscular formulations have immediate or quick absorption, respectively. These advantages are particularly useful in patients with depression and psychomotor agitation. Intravenous and intramuscular formulations help patients with poor adherence or inability (e.g., post-surgery) to take oral medications. Trazodone displays a good tolerability profile, with a low risk for weight gain, sexual dysfunction, and anticholinergic effects such as dry mouth, constipation, and urinary retention. Finally, the PERK/EIF-2a pathway inhibition suggests trazodone as a potential neuroprotective activity in chronic neurodegenerative disorders characterised by protein misfolding, such as Alzheimer's disease, in which comorbid depression complicates the management of patients.

\section{References}

1 Golden RN, Dawkins K, Nicholas L. Trazodone and nefazodone. In: Schatzberg AF, Nemeroff CB, Eds. The American psychiatric publishing textbook of psychopharmacology, Fourth Ed. Washington, D.C.: American Psychiatric Publishing, Inc., 2009, p. 403.
2 Fagiolini A, Comandini A, Catena Dell'Osso M, et al. Rediscovering trazodone for the treatment of major depressive disorder [published correction appears in CNS Drugs. 2013;27:677]. CNS Drugs 2012;26:1033-49. https://doi. org/10.1007/s40263-012-0010-5

3 Stahl SM. Mechanism of action of trazodone: a multifunctional drug. CNS Spectr 2009;14:536-46. https://doi. org/10.1017/s1092852900024020

4 Goracci A, Forgione RN, De Giorgi R, et al. Practical guidance for prescribing trazodone extended-release in major depression. Expert Opin Pharmacother 2016;17:433-41. https://doi.org/10.1517/14656566.2016.1133587

5 Bossini L, Casolaro I, Koukouna D, et al. Off-label uses of trazodone: a review. Expert Opin Pharmacother 2012;13:1707-17. https://doi.org/10.1517/14656566.20 12.699523

6 Bossini L, Coluccia A, Casolaro I, et al. Off-label trazodone prescription: evidence, benefits and risks. Curr Pharm Des 2015;21:3343-51. https://doi.org/10.2174/13816128216 66150619092236

7 American Psychiatric Association. Diagnostic and statistical manual of mental disorders, Fifth Ed. Washington, DC: American Psychiatric Association 2013.

8 Fried El, Nesse RM. Depression is not a consistent syndrome: an investigation of unique symptom patterns in the STAR $^{*}$ D study. J Affect Disord 2015;172:96-102. https:// doi.org/10.1016/j.jad.2014.10.010

9 Park SC, Kim YK. Diagnostic issues of depressive disorders from kraepelinian dualism to the Diagnostic and statistical manual of mental disorders, Fifth Ed. Psychiatry Investig 2019;16:636-44. https://doi.org/10.30773/pi.2019.09.07

10 Fang Y, Wu Z. Advance in diagnosis of depressive disorder. Adv Exp Med Biol 2019;1180:179-91. https://doi. org/10.1007/978-981-32-9271-0_9

11 Chekroud AM, Gueorguieva R, Krumholz HM, et al. Reevaluating the efficacy and predictability of antidepressant treatments: a symptom clustering approach. JAMA Psychiatry 2017;74:370-8. https://doi.org/10.1001/jamapsychiatry.2017.0025

12 https://www.cdc.gov/aging/mentalhealth/depression.htm

13 https://www.nia.nih.gov/health/depression-and-olderadults

14 Bassiony MM. Depression and neurological disorders. Neurosciences 2009;14:220-9.

15 Khouzam HR. A review of trazodone use in psychiatric and medical conditions. Postgrad Med 2017;129:140-8. https://doi.org/10.1080/00325481.2017.1249265

16 Liu B, Liu J, Wang M, et al. From serotonin to neuroplasticity: evolvement of theories for major depressive disorder. Front Cell Neurosci 2017;11:305. https://doi.org/10.3389/ fncel.2017.00305

17 Montalbano A, Mlinar B, Bonfiglio F, et al. Dual inhibitory action of trazodone on dorsal raphe serotonergic neurons through 5-HT1A receptor partial agonism and $\alpha 1$ adrenoceptor antagonism. PLoS One 2019;14:e0222855. https://doi.org/10.1371/journal.pone.0222855

18 Odagaki Y, Toyoshima R, Yamauchi T. Trazodone and its 
active metabolite m-chlorophenylpiperazine as partial agonists at 5-HT1A receptors assessed by [35S] GTPgammaS binding. J Psychopharmacol 2005;19:235-41. https://doi. org/10.1177/0269881105051526

19 Serretti A, Chiesa A. Treatment-emergent sexual dysfunction related to antidepressants: a meta-analysis. J Clin Psychopharmacol 2009;29:259-66. https://doi.org/10.1097/ JCP.0b013e3181a5233f

20 Settimo L, Taylor D. Evaluating the dose-dependent mechanism of action of trazodone by estimation of occupancies for different brain neurotransmitter targets. J Psychopharmacol 2018;32:96-104. https://doi. org/10.1177/0269881117742101

21 Camargos EF, Louzada LL, Quintas JL, et al. Trazodone improves sleep parameters in Alzheimer disease patients: a randomised, double-blind, and placebo-controlled study. Am J Geriatr Psychiatry 2014;22:1565-74. https://doi. org/10.1016/j.jagp.2013.12.174

22 Cuomo A, Ballerini A, Bruni AC, et al. Clinical guidance for the use of trazodone in major depressive disorder and concomitant conditions: pharmacology and clinical practice. Riv Psichiatr 2019;54:137-49. https://doi. org/10.1708/3202.31796

23 Pyke RE. Trazodone in sexual medicine: underused and overdosed? Sex Med Rev 2018;8:206-16. https://doi. org/10.1016/j.sxmr.2018.08.003

24 Chokka PR, Hankey JR. Assessment and management of sexual dysfunction in the context of depression. Ther Adv Psychopharmacol 2018;8:13-23. https://doi. org/10.1177/2045125317720642

25 Rotzinger S, Fang J, Baker G.B. Trazodone is metabolised to m-chlorophenylpiperazine by CYP3A4 from human sources. Drug Metab Dispos 1998;26:572-5.

26 EMCDDA (https://www.emcdda.europa.eu/attachements. cfm/att_136859_EN_Europol-EMCDDA_Active_Monitoring_Report_mCPP_290307.pdf).

27 Schmitt W. General approach for the calculation of tissue to plasma partition coefficients. Toxicolln Vitro 2008;22:45767. https://doi.org/10.1016/j.tiv.2007.09.010

28 FDA (www.accessdata.fda.gov/drugsatfda_docs/ nda/2010/022411s000MedR.pdf).

29 FDA (www.accessdata.fda.gov/drugsatfda_docs/ label/2015/071196s062lbl.pdf).

30 Fagiolini A, Albert U, Ferrando L, et al. A randomised, double-blind study comparing the efficacy and safety of trazodone once-a-day and venlafaxine extended-release for the treatment of patients with major depressive disorder. Int Clin Psychopharmacol 2020;35:137-46. https:// doi.org/10.1097/YIC.0000000000000304

31 Osváth P. Az időskori depresszió és agitáció korszerü kezelése - a trazodon alkalmazásának lehetőségei [Current treatment of depression and agitation in the elderly - clinical use of trazodone]. Neuropsychopharmacol Hung 2013;15:147-55. Hungarian.

32 Shi S, Klotz U. Age-related changes in pharmacokinetics. Curr Drug Metab 2011;12:601-10. https://doi. org/10.2174/138920011796504527
33 Ganguli M. Depression, cognitive impairment and dementia: why should clinicians care about the web of causation? Indian J Psychiatry 2009;51(Suppl 1):S29-34.

34 López-Pousa S, Garre-Olmo J, Vilalta-Franch J, et al. Trazodone for Alzheimer's disease: a naturalistic follow-up study. Arch Gerontol Geriatr 2008;47:207-15. https://doi. org/10.1016/j.archger.2007.07.010

35 Lebert F, Stekke W, Hasenbroekx C, et al. Frontotemporal dementia: a randomised, controlled trial with trazodone. Dement Geriatr Cogn Disord 2004;17:355-9. https://doi. org/10.1159/000077171

36 Halliday M, Radford H, Zents KAM, et al. Repurposed drugs targeting elF2 $\alpha$-P-mediated translational repression prevent neurodegeneration in mice. Brain 2017;140:176883. https://doi.org/10.1093/brain/awx074

37 Hoozemans JJ, van Haastert ES, Eikelenboom P, et al. Activation of the unfolded protein response in Parkinson's disease. Biochem Biophys Res Commun 2007;354:70711. https://doi.org/10.1016/j.bbrc.2007.01.043

38 Nijholt DA, Nölle A, van Haastert ES, et al. Unfolded protein response activates glycogen synthase kinase-3 via selective lysosomal degradation. Neurobiol Aging 2013;34:1759-71. https://doi.org/10.1016/j.neurobiolaging.2013.01.008

39 Stutzbach LD, Xie SX, Naj A.C. et al. The unfolded protein response is activated in disease-affected brain regions in progressive supranuclear palsy and Alzheimer's disease. Acta Neuropathol Commun 2013;1:31. https://doi. org/10.1186/2051-5960-1-31

40 Daniele S, Zappelli E, Martini C. Trazodone regulates neurotrophic/growth factors, mitogen-activated protein kinases and lactate release in human primary astrocytes. J Neuroinflammation 2015;12:225. https://doi.org/10.1186/ s12974-015-0446-x

41 Coupland CAC, Hill T, Dening T, et al. Anticholinergic drug exposure and the risk of dementia: a nested case-control study. JAMA Intern Med 2019;179:1084-93. https://doi. org/10.1001/jamainternmed.2019.0677

42 Gerretsen P, Pollock BG. Drugs with anticholinergic properties: a current perspective on use and safety. Expert Opin Drug Saf 2011;10:751-65. https://doi.org/ 10.1517/14740338.2011.579899.

43 La AL, Walsh CM, Neylan TC, et al. Long-Term Trazodone Use and Cognition: A Potential Therapeutic Role for SlowWave Sleep Enhancers. J Alzheimers Dis. 2019;67(3):911 921. https://doi.org/10.3233/JAD-181145

44 Jaffer KY, Chang T, Vanle B, et al. Trazodone for insomnia: a systematic review. Innov Clin Neurosci 2017;14:24-34.

45 Burke AD, Goldfarb D, Bollam P, et al. Diagnosing and treating depression in patients with Alzheimer's disease. Neurol Ther 2019;8:325-50. https://doi.org/10.1007/ s40120-019-00148-5

46 Camargos EF, Pandolfi MB, Freitas MP, et al. Trazodone for the treatment of sleep disorders in dementia: an open-label, observational and review study. Arq Neuropsiquiatr 2011;69:44-9. https://doi.org/10.1590/s0004$282 \times 2011000100010$ 
47 Suzuki H, Yamadera $H$, Nakamura S, et al. Effects of trazodone and imipramine on the biological rhythm: an analysis of sleep EEG and body core temperature. J Nippon Med Sch 2002;69:333-41. https://doi.org/10.1272/ jnms.69.333

48 Roth AJ, McCall WV, Liguori A. Cognitive, psychomotor and polysomnographic effects of trazodone in primary insomniacs. J Sleep Res 2011;20:552-8. https://doi. org/10.1111/j.1365-2869.2011.00928.x

49 Verdolini N, Perugi G, Samalin L, et al. BRIDGE-II-Mix Study Group. Aggressiveness in depression: a neglected symptom possibly associated with bipolarity and mixed features. Acta Psychiatr Scand 2017;136:362-72. https:// doi.org/10.1111/acps.12777

50 Lyketsos CG, Steele C, Galik E, et al. Physical aggression in dementia patients and its relationship to depression. Am J Psychiatry 1999;156:66-71.

51 Menon AS, Gruber-Baldini AL, Hebel JR, et al. Relationship between aggressive behaviors and depression among nursing home residents with dementia. Int J Geriatr Psychiatry 2001;16:139-46.

52 Saletu-Zyhlarz GM, Anderer P, Arnold O, et al. Confirmation of the neurophysiologically predicted therapeutic effects of trazodone on its target symptoms depression, anxiety and insomnia by postmarketing clinical studies with a controlled-release formulation in depressed outpatients. Neuropsychobiology 2003;48:194-208. https://doi. org/10.1159/000074638

$53 \mathrm{Kim}$ JS. Post-stroke mood and emotional disturbances: pharmacological therapy based on mechanisms. J Stroke 2016;18:244-55. https://doi.org/10.5853/jos.2016.01144

54 Raffaele R, Rampello L, Vecchio I, et al. Trazodone therapy of the post-stroke depression. Arch Gerontol Geriatr 1996;22(Suppl 1):217-20. https://doi.org/10.1016/01674943(96)86939-1

55 Hamadjida A, Nuara SG, Gourdon JC, et al. Trazodone alleviates both dyskinesia and psychosis in the parkinsonian marmoset model of Parkinson's disease. J Neural Transm (Vienna) 2018;125:1355-60. https://doi.org/10.1007/ s00702-017-1830-8

56 Ballerio M, Politi P, Crapanzano C, et al. Clinical effectiveness of parenteral trazodone for the management of psychomotor activation in patients with bipolar disorder. Neuro Endocrinol Lett 2018;39:205-8.

57 Glass OM, Hermida AP, Hershenberg R, et al. Considerations and current trends in the management of the geriatric patient on a consultation-liaison service. Curr Psychiatry Rep 2020;22:21. https://doi.org/10.1007/s11920-02001147-2

58 Stryjer R, Rosenzcwaig S, Bar F, et al.Trazodone for the treatment of neuroleptic-induced acute akathisia: a placebo-controlled, double-blind, crossover study. Clin Neuropharmacol 2010;33:219-22. https://doi.org/10.1097/ WNF.0b013e3181ee7f63

59 Gale CK. The treatment of generalised anxiety disorder. A systematic review. Panminerva Med 2002;44:283-6.

60 Maher MJ, Rego SA, Asnis GM. Sleep disturbances in patients with post-traumatic stress disorder: epidemiology, impact and approaches to management. CNS Drugs 2006;20:567-90.

61 Maremmani I, Spera V, Maremmani A, et al. Is trazododone contramid useful in inducing patients to refrain from using cocaine after detoxification, so avoiding early relapse? A case series. Addict Disord Their Treat 2019;18:105-12. https://doi.org/10.1097/ADT.0000000000000157

62 Tolliver BK, Anton RF. Assessment and treatment of mood disorders in the context of substance abuse. Dialogues Clin Neurosci 2015;17:181-190.

63 Friedmann PD, Rose JS, Swift R, et al. Trazodone for sleep disturbance after alcohol detoxification: a double-blind, placebo-controlled trial. Alcohol Clin Exp Res 2008;32:165260. https://doi.org/10.1111/j.1530-0277.2008.00742.x

64 https://www.accessdata.fda.gov/drugsatfda_docs/ label/2015/071196s062lbl.pdf

65 Schatzberg AF, DeBattista C. Schatzberg's manual of clinical psychopharmacology, ninth edition. Washington DC: American Psychiatric Association Publishing 2019, pp 96-105.

66 Kaplan BJ, Sadock VA. Kaplan and Sadock's pocket handbook of clinical psychiatry, Sixth Ed. Baltimore (P.A.): Wolters Kluwer 2018.

67 Farrell B, Shamji S, Ingar N. Reducing fall risk while managing pain and insomnia: addressing polypharmacy in an 81-year-old woman. Can Pharm J (Ott) 2013;146:335-41. https://doi.org/10.1177/1715163513504529

68 Saenz de Tejada I, Ware JC, Blanco R, et al. Pathophysiology of prolonged penile erection associated with trazodone use. J Urol 1991;145:60-4.

69 Warner MD, Peabody CA, Whiteford HA, et al. Trazodone and priapism. J Clin Psychiatry 1987;48:244-5.

70 Sood S, James W, Bailon MJ. Priapism associated with atypical antipsychotic medications: a review. Int Clin Psychopharmacol 2008;23:9-17. https://doi.org/10.1097/ YIC.0b013e3282f1c1ef

71 Alvarez W Jr, Pickworth KK. Safety of antidepressant drugs in the patient with cardiac disease: a review of the literature. Pharmacotherapy 2003;23:754-71. https://doi. org/10.1592/phco.23.6.754.32185

72 Armstrong SEM, Brown HK, Shorey C, et al. No association between trazodone and corrected-qt prolongation in older adults. J Clin Psychopharmacol 2019;39:528-30. https://doi.org/10.1097/JCP.0000000000001102

$73 \mathrm{NHS}$ (https://www.nhs.uk/conditions/dizziness).

74 Maes M, Westenberg H, Van Doolaeghe E, et al. Effects of trazodone and fluoxetine in the treatment of major depression: therapeutic pharmacokinetic and pharmacodynamic interactions through formation of meta-chlorophenylpiperazine. J Clin Psychopharmacol 1997;17:358-64.

75 Chen HC, Tsai SJ. Trazodone-induced severe headache. Psychiatry Clin Neurosci 2011;65:681-2. https://doi. org/10.1111/j.1440-1819.2011.02276.x

76 Jaffer KY, Chang T, Vanle B, et al. Trazodone for Insomnia: a systematic review. Innov Clin Neurosci 2017;14:24-34. 
77 Murray B. A practical approach to excessive daytime sleepiness: a focused review. Can Respir J 2016; 2016. https://doi.org/10.1155/2016/4215938

78 NHS (https://www.nhs.uk/conditions/excessive-daytimesleepiness-hypersomnia).

79 Daly C. Oral and dental effects of antidepressants. Aust Prescr 2016;39:84. https://doi.org/10.18773/austprescr.2016.035

80 Gaffney RR, Schreibman IR. Serotonin Syndrome in a patient on trazodone and duloxetine who received fentanyl following a percutaneous liver biopsy. Case Rep Gastroenterol 2015;9:132-6.

81 Levine M, Ruha A-M. Antidepressants. In: Walls RM, Hockberger RS, Gausche-Hill M, Eds. Rosen's emergency medicine: concepts and clinical practice. 9th Ed. Philadelphia, PA: Elsevier 2018, chap. 146.

82 Shin JJ, Saadabadi A. Trazodone. [Updated 2020 May 28]. In: StatPearls [Internet]. Treasure Island (F.L.): StatPearls Publishing 2020;Jan.

83 Carvalhana S, Oliveira A, Ferreira P, et al. Acute liver failure due to trazodone and diazepam. GE Port J Gastroenterol 2017;24:40-2. https://doi.org/10.1159/000450878

84 Torrino Medica: (https://www.torrinomedica.it/schedefarmaci/trittico).

85 Friedrich MJ. Depression Is the leading cause of disability around the world. JAMA 2017;317:1517. https://doi. org/10.1001/jama.2017.3826 